\title{
AVALIAÇÃO DA QUALIDADE MICROBIOLÓGICA DE FRUTOS MINIMAMENTE PROCESSADOS COMERCIALIZADOS EM SUPERMERCADOS DE FORTALEZA ${ }^{1}$
}

\author{
NEUMA MARIA DE SOUZA PINHEIRO², EVÂNIA ALTINA TEIXEIRA DE FIGUEIREDO ${ }^{3}$, RAIMUNDO WILANE DE \\ FIGUEIREDO ${ }^{3}$, GERALDO ARRAES MAIA ${ }^{3}$, PAULO HENRIQUE MACHADO DE SOUZA ${ }^{2}$
}

\begin{abstract}
RESUMO - O processamento mínimo tem sido descrito como a manipulação, o preparo, embalagem e a distribuição de produtos agrícolas, através de procedimentos como seleção, limpeza, lavagem, descascamento e corte, que não afetem suas características organolépticas, agregando valor aos mesmos. Vários fatores limitam o consumo destes produtos, os quais estão envolvidos na sua vida útil, tais como: aumento da respiração e da produção de etileno, escurecimento enzimático, descoloração da superfície, perda de água e, sobretudo, alterações microbiológicas. No presente trabalho, o enfoque foi dado a este ultimo fator. Foram analisadas 20 amostras de goiaba, manga, melão japonês, mamão formosa e abacaxi minimamente processados e comercializados em supermercados da cidade de Fortaleza-CE, considerando-se a quantificação de coliformes totais, fecais, bolores e leveduras, e detecção de bactérias potencialmente patogênicas, tais como Salmonella sp e Staphylococcus coagulase positivo. Através dos resultados deste trabalho, permitiu-se sugerir a necessidade de controle de qualidade, observando as boas práticas de fabricação, para posterior implementação de um sistema preventivo de APPCC, análise de perigos e pontos críticos de controle, para se assegurar um produto saudável e seguro para o consumidor.
\end{abstract}

Termos para indexação: frutos, microbiologia, processamento mínimo.

\section{EVALUATION OF MICROBIOLOGICAL QUALITY OF FRUITS MINIMALLY PROCESSED COMMERCIALIZED IN SUPERMARKETS IN FORTALEZA}

\begin{abstract}
Minimal processing has been described as handling, preparing, packing, and distribution of agricultural products, throughout certain procedures, such as selection, cleaning, peeling and cutting, that do not affect the sensory characteristics of the products, aggregating value to them. There are some factors that limit the consumption of these products related to their shelf-life, such as increasing of respiration rate and of ethylene production, enzymatic browning, surface white discoloration, water loss and microbiological changes. This work has focused on this last factor. Twenty samples of guava, mango, melon var. "japonês", papaya var. "formosa" and pineapple, commercialized in Fortaleza-CE, were analyzed considering the quantification of fecal and total coliforms, yeasts and molds and searching for potentially pathogenic bacteria such as Staphylococcus coagulase positive and Salmonella sp. Based on the results, it could be suggested the need of quality control, observing the good manufacturing practices, to further implementation of a preventive HACCP system, assuring to the consumer a healthy and a safety product. Index terms: fruits, microbiology, minimally processed.
\end{abstract}

\section{INTRODUÇÃO}

A demanda de vegetais frescos cortados tem crescido devido às suas características de frescor e conveniência, entretanto a produção, a distribuição, a qualidade e a segurança de tais frutos e hortaliças são limitadas pelos conhecimentos que se têm acerca desse tipo de produto (Bolin \& Huxsoll, 1989).

Um alimento é um recinto ecológico completo e dinâmico composto por muitos microambientes. As etapas de elaboração dos produtos minimamente processados e os próprios processos respiratórios dos vegetais afetam estes microambientes e, conseqüentemente, o desenvolvimento microbiano (BRACKETT, 1997).

A microbiologia de frutos minimamente processados é multifatorial, dependendo do tipo de fruto $(\mathrm{pH}$, atividade de água, nutrientes), sua procedência, etapas de processamento (lavagem, sanificação, descascamento, corte, embalagem, temperatura de armazenamento) e condições higiênico-sanitárias do manipulador, dos equipamentos e utensílios, bem como do ambiente.

A qualidade microbiológica dos alimentos minimamente processados está relacionada à presença de microrganismos deteriorantes que irão influenciar nas alterações sensoriais do produto durante sua vida útil. Contudo, a maior preocupação está relacionada a sua segurança, não apresentando contaminação por agentes químicos, físicos e microbiológicos em concentrações prejudiciais à saúde (Vanetti, 2004).

A Resolução RDC N012, de 2 de janeiro de 2001, do Ministério da Saúde (Brasil, 2001), estabelece os padrões microbiológicos sanitários para alimentos, não existindo padrões específicos para os frutos minimamente processados. Estes podem ser inseridos no grupo de alimentos designados como: " frutas frescas, in natura, preparadas (descascadas ou selecionadas ou fracionadas), sanificadas, refrigeradas ou congeladas, para consumo direto", cuja tolerância máxima para amostra indicativa é de $5 \times 10^{2} \mathrm{NMP}^{-1} \mathrm{gu}^{-1} \mathrm{UC}^{-g^{-1}}$ de coliformes a $45^{\circ} \mathrm{C}$ e ausência de Salmonella sp em 25g.

No Brasil, nos anos de 1996 e de 1998 a 2000, foram registrados 192 surtos de infecção alimentar com 12.188 enfermos e 3 mortes, tendo sido a Salmonella sp a responsável pela maioria, com incidência em 76,56\% destas ocorrências. As hortaliças de folhas e raízes foram responsáveis por 19 (9,9\%) surtos (SIRVETA, 2002). No Canadá, Todd (1989) estimou que somente 2 a $5 \%$ dos casos de doenças transmitidas por alimentos durante os anos de 1983 e 1984 estavam relacionados a frutos e hortaliças.

Há poucas pesquisas sobre a microbiologia de frutos minimamente processados. A determinação da incidência de microrganismos deteriorantes e patogênicos nestes produtos, além de ser uma fonte de dados para especificação de padrões microbiológicos, serve de subsídio para o estabelecimento de um treinamento nos aspectos tecnológicos de produtos minimamente processados, bem como em boas práticas de fabricação.

Através dessa pesquisa, visou-se a avaliar a qualidade e a segurança microbiológica de frutos minimamente processados em amostras de goiaba vermelha, manga, melão japonês, mamão formosa e abacaxi comercializados em supermercados de Fortaleza-CE, bem como verificar se atendem aos padrões de inocuidade estabelecidos pela RDC $\mathrm{N}^{\circ} 12$ de 02 janeiro de 2001 (Brasil, 2001).

\section{MATERIALEMÉTODOS}

Foram analisadas 20 amostras de frutos minimamente processados (goiaba vermelha, manga, melão japonês, mamão formosa e abacaxi), totalizando 100 amostras.

Os frutos estavam acondicionados em bandejas de poliestireno

${ }^{1}$ (Trabalho 125/2004). Recebido: 07/10/2004. Aceito para publicação: 19/04/2005.

${ }^{2}$ UFC - Mestre em Tecnologia de Alimentos, C.P. 12168, CEP 60356000, Fortaleza-CE.

${ }^{3}$ UFC - Professor do Departamento de Tecnologia de Alimentos/Centro de Ciências Agrárias/Universidade Federal do Ceará. C.P.:12168. Fortaleza-CE. frutos@ ufc.br. 
expandido, envolto por filme de polietileno, e armazenados em balcões refrigerados sem termômetro ou sobre gelo, em supermercados de Fortaleza-CE. Logo após a coleta, as amostras foram transportadas em caixas térmicas contendo gelo, até o laboratório de Microbiologia de Alimentos do Departamento de Tecnologia de Alimentos da Universidade Federal do Ceará, onde foram imediatamente analisadas.

Assepticamente, após homogeneização dos frutos, uma unidade analítica de $25 \mathrm{~g}$ da amostra foi transferida para $225 \mathrm{~mL}$ de água peptonada $0,1 \%$ e, a partir desta, foram preparadas diluições até $10^{-4}$.

As análises microbiológicas foram realizadas segundo metodologias descritas em American Public Health Association (APHA 2001). Para coliformes totais e fecais, foi utilizada a técnica do Número Mais Provável (NMP.g ${ }^{-1}$ ). A contagem de bolores e leveduras (UFC. ${ }^{-1}$ ) foi realizada por espalhamento em superfície em meio de ágar batata acidificado ( $\mathrm{pH}$ final 3,5) e incubado a $25^{\circ} \mathrm{C}$, por 3 a 5 dias. A contagem de Staphylococcus coagulase positivo (UFC. ${ }^{-1}$ ) foi realizada por espalhamento em superfície em meio de ágar Baird-Parker e incubado a $35^{\circ} \mathrm{C}$, por $48 \mathrm{~h}$. A confirmação das colônias foi efetuada pelos seguintes ensaios: coloração de Gram, teste de catalase, teste de coagulase e teste de termonuclease. A pesquisa de Salmonella sp em $25 \mathrm{~g}$ de fruto foi realizada com pré-enriquecimento, em caldo lactosado, com incubação a $35^{\circ} \mathrm{C}$, por $24 \mathrm{~h}$, seguida de enriquecimento seletivo, em caldo tetrationato e caldo Rappaport incubados, respectivamente, a $35^{\circ} \mathrm{Ce} 42^{\circ} \mathrm{C}$, por $24 \mathrm{~h} . \mathrm{O}$ isolamento de Salmonella sp foi realizado em ágar Xilose Lisina Desoxicolato, ágar Hectoen e ágar Bismuto sulfito incubados a $35^{\circ} \mathrm{C}$, por 24-48h. A identificação de Salmonella sp foi realizada por teste sorológico somático e pelas seguintes determinações: teste de TSI, teste de LIA, coloração de Gram, teste de urease, teste de vermelho de metila e VogesProskauer, teste de malonato, teste de indol, teste de fermentação do dulcitol e teste de urease.

\section{RESULTADOS E DISCUSSÃO}

Das 100 amostras de frutos minimamente processados analisados (goiaba, manga, melão, mamão e abacaxi), 25 (25\%), estavam contaminadas com Salmonella sp e 28 (28\%), apresentavam coliformes fecais em valores superiores a 5,0 x $10^{2} \mathrm{NMP}^{-1}{ }^{-1}$. Estas contaminações indicam que 43 amostras estavam impróprias para o consumo humano, segundo a RDC N ${ }^{\circ} 12$ de 02 janeiro de 2001 (Brasil, 2001).

Não foi observada a presença de Staphylococcus coagulase positivo nas amostras analisadas, embora no processamento mínimo de frutos ocorra intensa manipulação. Provavelmente, as condições intrínsecas dos frutos e as condições ambientais não favoreceram o estabelecimento dessas bactérias.

Foram isolados, nas amostras analisadas, bactérias do grupo coliformes, Salmonella sp, bolores e leveduras, constatando-se que a microbiota associada a frutos minimamente processados é bastante diversificada podendo a contaminação, originar-se em várias etapas: durante a produção no campo, manuseio pós-colheita, transporte, armazenamento e, principalmente, durante o processamento.

As amostras de goiaba, manga e mamão formosa minimamente processadas analisadas apresentaram a incidência de coliformes totais de $<3$ NMP.g $^{-1}$ a 2,4 x $10^{6}$ NMP.g $^{-1}$ (Figura 1). Para estes produtos, a ocorrência de coliformes fecais foi, respectivamente: $<3 \mathrm{NMP}^{-1}{ }^{-1} \mathrm{a} 4,6 \mathrm{x}$

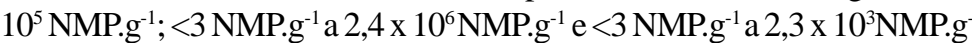
${ }^{1}$ (Figura 2). Das 20 amostras de abacaxi minimamente processadas analisadas, constatou-se a presença de coliformes totais e coliformes fecais com valores entre $<3$ NMP.g ${ }^{-1}$ a $2,4 \times 10^{3} \mathrm{NMP}^{-1} \mathrm{~g}^{-1}$. Contudo, nas amostras de melão japonês minimamente processados analisadas, as contagens de coliformes totais variaram de 4,0 $\times 10^{2} \mathrm{NMP.g}^{-1}$ a 2,4 x $10^{6}$ NMP.g ${ }^{-1}$ e coliformes fecais de $<3 \mathrm{NMP}^{-1}{ }^{-1}$ a $1,5 \times 10^{6} \mathrm{NMP}^{-1}{ }^{-1}$ (Figuras 1 e 2).

Dos frutos minimamente processados analisados, o que apresentou menor contagem de coliformes totais e fecais foi o abacaxi minimamente processado. Isto pode ser justificado pelo $\mathrm{pH}$ ácido deste fruto. Entretanto, maior incidência deste microrganismo foi encontrada

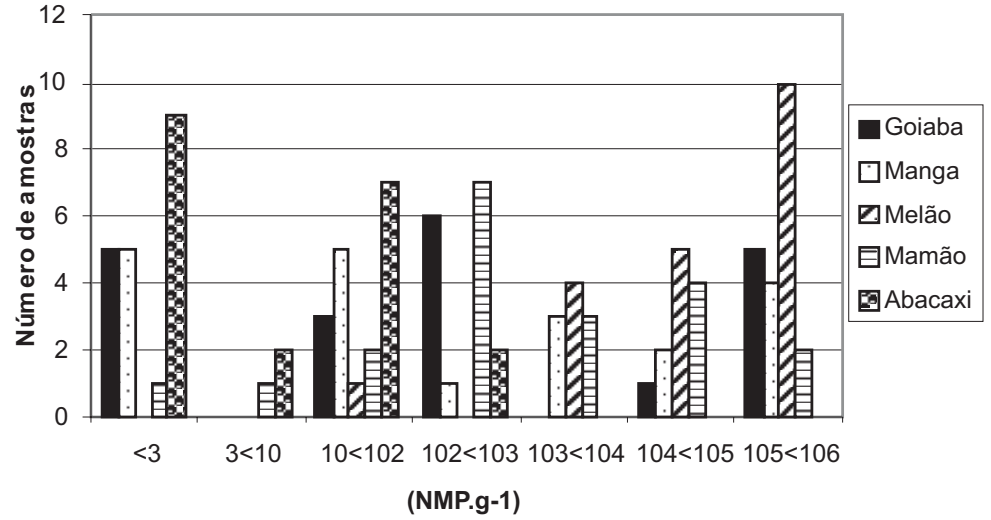

FIGURA 1- Coliformes totais (NMP.g ${ }^{-1}$ ) em 20 amostras de cada um dos frutos minimamente processados analisados.

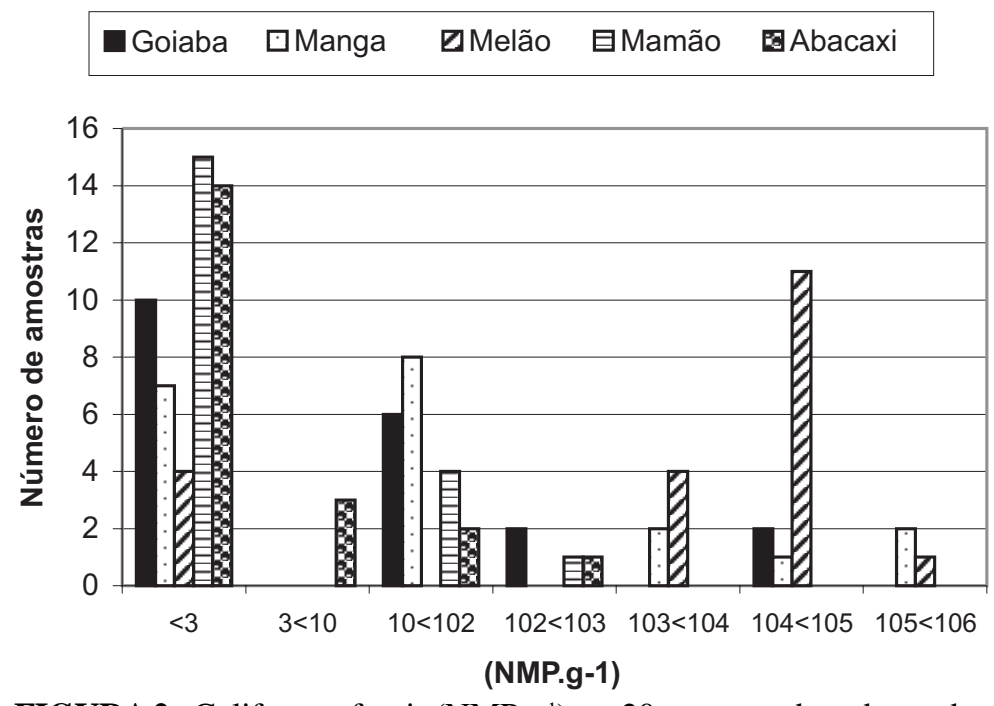

FIGURA 2 - Coliformes fecais (NMP.g ${ }^{-1}$ ) em 20 amostras de cada um dos frutos minimamente processados analisados.

em melões minimamente processados. Conforme Anderson (1989), os coliformes totais não apresentam boa especificidade como indicador fecal, podendo ser encontrados em ambiente extra-intestinal, inclusive em plantas.

A presença de coliformes fecais indica que as frutas minimamente processadas tiveram contato direto e/ou indireto com fezes, uma vez que a Escherichia coli não faz parte da microflora normal de produtos frescos, por apresentar habitat exclusivo no intestino do homem e animais de sangue quente. Além de indicar a possível presença de enteropatógenos, várias cepas de E.coli são patogênicas ao homem.

SILVA (2001), ao estudar as características microbiológicas do abacaxi minimamente processado, encontrou coliformes totais variando de 1,3 a 46 NMP.g ${ }^{-1}$, durante o armazenamento, não detectando a presença de coliformes fecais. Contudo, Palu et al. (2002), ao analisarem 15 amostras de frutas prontas para consumo, encontraram 3 amostras de mamão e uma de melão com níveis de coliformes totais entre $10^{3}$ a $10^{4} \mathrm{NMP}^{-1} \mathrm{e}^{-1}$ contaminação com coliformes fecais em uma amostra de melão $\left(3,5 \times 10^{3}\right.$ NMP.g $\left.{ }^{-1}\right)$ e outra de mamão $\left(2,4 \times 10^{4} \mathrm{NMP.g}^{-1}\right)$.

Os produtos minimamente processados ficam expostos a todo tipo de contaminação, e, logo após a remoção da casca, que funciona como barreira parcial, a penetração de microrganismos é facilitada. Outro fator que deve ser considerado são os aspectos tecnológicos que devem ser aplicados a cada fruto. Dentre estes, destaca-se o resfriamento do fruto antes do corte, que evita a exsudação e, conseqüentemente, limita o rápido desenvolvimento bacteriano. Durante o processamento de frutos minimamente processados, a aplicação de boas práticas de manipulação e o controle de temperatura são indispensáveis para minimizar a contaminação e controlar o desenvolvimento microbiano. Em geral, os frutos não podem ser sanitizados após as etapas de descasque e corte, ficando expostos ao aumento na população de microrganismos. 
Nos supermercados onde os frutos minimamente processados foram produzidos e embalados, a qualidade da água, a estrutura física destinada exclusivamente ao processamento dos frutos, o armazenamento das embalagens, a higienização de equipamentos e utensílios, bem como o treinamento dos manipuladores, são de fundamental importância para a segurança e a qualidade microbiológica desses produtos.

Verificou-se maior incidência de Salmonella sp nas amostras de mamão $10(50 \%)$. Nos outros frutos minimamente processados, a contaminação com o citado patógeno ocorreu em: melão 5(25\%), abacaxi $5(25 \%)$, goiaba 3(15\%) e manga 2(10\%)(Figura 3). Segundo Nguyen-The \& Carlin (1994), nos EUA, a Salmonella proveniente de melão em salada de frutas e melancia, foi indicada como responsável pela infecção alimentar.

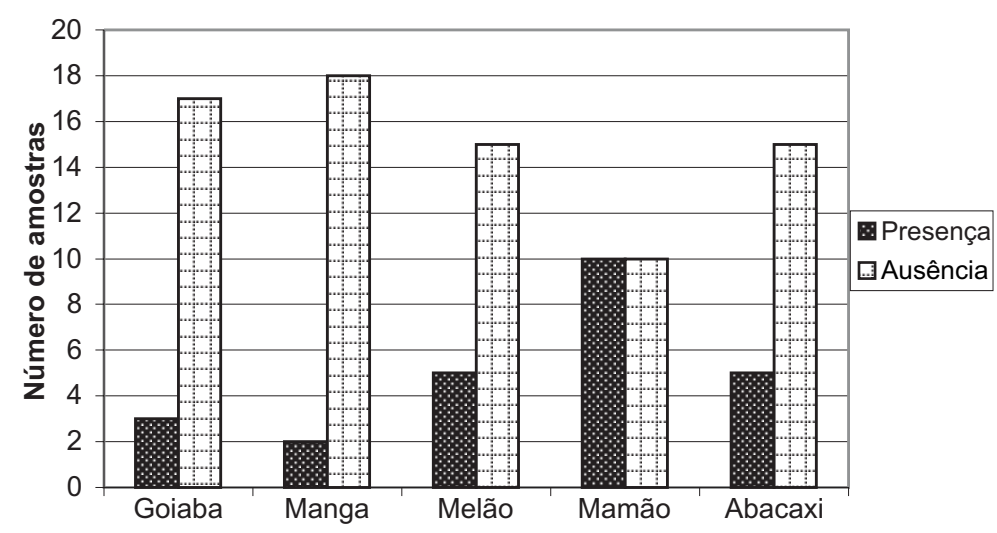

FIGURA 3 - Salmonella sp. $25 \mathrm{~g}^{-1}$ em 20 amostras de cada um dos frutos minimamente processados analisados.

A ocorrência de 5(25\%) amostras de abacaxi minimamente processadas contaminadas com Salmonella sp sugere uma contaminação recente, possivelmente ocorrida durante o processamento, uma vez que o pH ácido desse fruto, aliado a uma estocagem sob refrigeração, restringe o desenvolvimento do citado patógeno. Contudo, Nguyen-The \& Carlin (1994) relatam a sobrevivência e o crescimento de Salmonella typhimurium em sucos de algumas variedades de maçãs, em pH 3,68 ou superior.

Durante a elaboração de frutos minimamente processados, a superfície dos frutos, a água, os equipamentos, os utensílios, as embalagens e o manipulador podem ser fontes de contaminação.O isolamento de bactérias do grupo coliformes e Salmonella sp indicam que as condições de armazenamento não foram eficientes. Conforme ICMSF (1996), o crescimento da maioria das espécies de Salmonella é impedido à temperatura $<5^{\circ} \mathrm{C}$ e, segundo Jay (1996), os coliformes em alimentos se desenvolvem muito lentamente em temperaturas $<5^{\circ} \mathrm{C}$, embora haja registro de crescimento em temperaturas de $3-6^{\circ} \mathrm{C}$.

Das 25 amostras de frutos minimamente processados, contaminadas com Salmonella sp, ocorreu o isolamento de coliformes fecais em 10(40\%), de coliformes totais em 12 (48\%) e em 3 (12\%) não houve detecção do grupo coliformes. Nguyen-The \& Carlin (1994) citam que a presença de Salmonella sp é correlacionada com a de E. Coli na maioria das avaliações microbiológicas em vegetais; contudo, essa evidência não foi observada no presente estudo.

A população de bolores e leveduras nos frutos minimamente processados variou entre $<10 \mathrm{UFC} \cdot \mathrm{g}^{-1}$ a $10^{8} \mathrm{UFC} \cdot \mathrm{g}^{-1}$, com o melão apresentando $15(75 \%)$ das amostras com elevadas contagens de $1,0 \mathrm{x}$ $10^{5}$ UFC.g $^{-1}$ a $1,8 \times 10^{6}$ UFC.g $^{-1}$ (Figura 4).

Nas amostras de frutas minimamente processadas analisadas, obteve-se uma contagem de bolores e leveduras que variou de $6,9 \times 10^{2}$ UFC. $g^{-1}$ a 6,0 x $10^{6}$ UFC.g ${ }^{-1}$ para goiaba; de 2,0 x $10^{2}$ UFC.g $^{-1}$ a 2,5 x $10^{5}$ UFC. $g^{-1}$ para manga; de $2,6 \times 10^{3} \mathrm{UFC}^{-1} \mathrm{~g}^{-1}$ a $1,8 \times 10^{6} \mathrm{UFC} \cdot \mathrm{g}^{-1}$ para melão; de $<10$ UFC. $g^{-1}$ a 8,3 x $10^{5}$ UFC.g $g^{-1}$ para mamão, e 2,7 x $10^{2}$ UFC. $^{-1}$ a 1,9 x $10^{7} \mathrm{UFC} \mathrm{g}^{-1}$ para abacaxi.

Em trabalho realizado com processamento mínimo de mamão formosa, Teixeira et al. (2000) verificaram uma contagem de bolores e

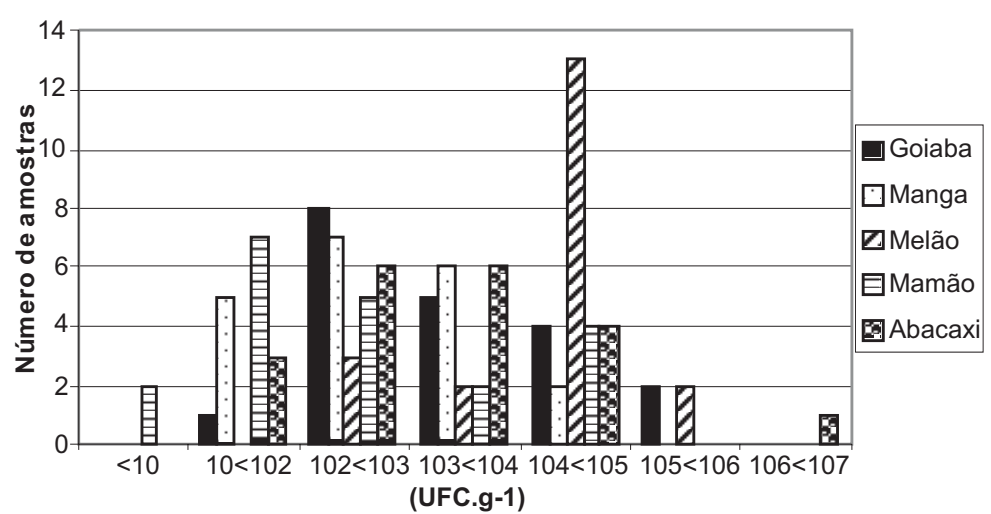

FIGURA 4 - Bolores e leveduras (UFC.g ${ }^{-1}$ ) em 20 amostras de cada um dos frutos minimamente processados analisados.

leveduras de $10^{3} \mathrm{UFC} / \mathrm{g}$, enquanto Palu et al. (2002) determinaram contagens de fungos em frutas frescas prontas para consumo, obtendo os seguintes valores: $3 \times 10^{6} \mathrm{UFC} . \mathrm{g}^{-1}$ para melão e entre $1,4 \times 10^{4} \mathrm{UFC} . \mathrm{g}^{-}$ ${ }^{1}$ a 1,4 x $10^{5} \mathrm{UFC}^{-g^{-1}}$ para mamão. Oliveira Junior et al. (2000) estudaram a estabilidade microbiológica de mamão, variedade Havaí, nas temperaturas de 5 e $10^{\circ} \mathrm{C}$, verificando que, a partir do $6^{0}$ dia a $10^{\circ} \mathrm{C}$, a contagem de bolores e leveduras atingiu níveis inaceitáveis. Os pesquisadores concluíram que a temperatura de $5^{\circ} \mathrm{C}$ é adequada para estocagem de mamão minimamente processado.

A presença de fungos em número elevado é indesejável, quanto à qualidade microbiológica, porque são capazes de produzir grandes variedades de enzimas, as quais provocam a deterioração de frutos. Além disso, muitos bolores podem produzir metabólicos tóxicos quando estão se desenvolvendo nos alimentos.

\section{CONCLUSÕES}

1. Uma grande parte dos frutos minimamente processados estudados estava imprópria para o consumo humano por apresentar microrganismos indicadores higiênico-sanitários, bem como microrganismos potencialmente patogênicos.

2. Foi evidenciada a ocorrência de Salmonella sp nos frutos minimamente processados amostrados, indicando a ocorrência de contaminação cruzada.

3. A inocuidade dos frutos ácidos minimamente processados não é garantida em função do seu $\mathrm{pH}$, uma vez que bactérias patogênicas podem ser veiculadas por esses alimentos.

4. A elevada população de bolores e leveduras em muitos dos frutos minimamente processados indica qualidade sanitária insatisfatória.

5. Os resultados deste trabalho sugerem a necessidade de aplicação das boas práticas de fabricação pelos estabelecimentos produtores e de uma efetiva fiscalização pela Vigilância Sanitária, para assegurar um produto saudável e seguro ao consumidor.

\section{REFERÊNCIAS}

ANDERSON, M.D.R.P. Microbiología alimentaria: detección de bactérias con significado higienico-sanitario. España: Ministerio de Sanidad y Consumo, 1989. 440p.

APHA. Compendium of methods for microbilogical examinaton of foods. 4. ed. Washingyton, 2001. p.515-516.

BOLIN, H, R; HUXSOLL, C. C. Storage stability of minimally processed fruit. Journal of Food Processing and Preservation, Trumbull, v.13, p.281-292, 1989.

BRACKETT, R. E, Alteración microbiológica y microrganismos patógenos de frutas y hortalizas refrigeradas minimamente orocesadas. In: Willey, Robert. C. (Ed.). Frutas e hortaliças minimamente processadas e refrigeradas. Zaragoza: Acríbia, 1997. p. 263-304.

BRASIL. Ministério Da Saúde. Resolução RDC N 12 de 02 de Janeiro de 2001.Brasília: ANVISA. 
ICMSF - International Commission on Microbiological. Specifications for foods, microorganisms in foods microbiological specifications of food pathogens. London: Blackie academic \& Professional, 1996. v.5.513p.

JAY, J. M. Modern food microbiology. $5^{\text {th }}$ ed. New York: Chapman \& Hall, 1996.661p

NGUYEN-THE, C; CARLIN, F. The Microbiology of minimally processed fresh fruits and vegetables. Critical Reviews Food Science Nutrition, Boca Raton, v.34, n.4, p.371-401, 1994.

OLIVEIRA, JR, et al. Avaliação da qualidade do mamão (Carica papaya L) MP armazenado em diferentes temperaturas. In: ENCONTRO NACIONAL SOBRE PROCESSAMENTO MÍNIMO DE FRUTAS E HORTALIÇAS, 2., 2000, Viçosa. Resumos... Viçosa: UFV, 2000. p.16.

PALU,A.A.;TIBANA, A.; TEIXEIRA, L.M., MIGUEL, M.A.L., PYRRHO, A.S.; LOPES, H.R. Avaliação microbiológica de frutas e hortaliças frescas, servidas em restaurantes self-service privados, da Universidade Federal do Rio de Janeiro. Revista Higiene Alimentar, São Paulo, v.16, n.100, p.67-71, 2002.

SILVA, C G. Estudo do efeito do tipo de corte, adição de cloreto e ácido ascórbico nas características físicas, físico-químicas e microbiológicas do abacaxi minimamente processado. 2001. $81 \mathrm{f}$.
Dissertação (Mestrado em tecnologia de Alimentos) - Centro de Ciências Agrárias, Universidade Federal do Ceará, Fortaleza-Ce, 2001.

SIRVETA - SISTEMA DE VIGILÂNCIA EPIDEMIOLÓGICA DE ENFERMIDADES TRANSMITIDAS POR ALIMENTOS. Sistema de información regional para la vigilancia epidemiológica de las enfermedades transmitidas por alimentos. Módulo dinâmico de acesso a la informatión. Disponível em: <http:// www.panalimentos.org/sirveta/e/index>.Acesso em: 25 de set. 2002.

TEIXEIRA, G.H.A.; DURIGAN, J.F.; MATTIUZ, B.H.; ROSSI JÚNIOR, O.D. Processamento mínimo de mamão "formosa”. In: ENCONTRO NACIONAL SOBRE PROCESSAMENTO MÍNIMO DE FRUTAS E HORTALIÇAS, 2., 2000, Viçosa. Resumos...Viçosa: UFV, 2000. p.14.

TODD, E.C.D. Preliminary Estimates of costs of foodborne disease in the United States. Journal of Food Protection, Des Moines, v.52, p.595-601, 1989.

VANETTI, M.C. D. Segurança microbiológica em produtos minimamente processados. In: ENCONTRO NACIONAL SOBRE PROCESSAMENTO MINIMO DE FRUTAS E HORTALIÇAS, 3., 2004. Viçosa- MG. Palestras, resumos e oficinas... Viçosa:.UFV, 2004. p.30-32. 